\title{
Virtual Communities and Social Change: Intertextuality in Saudi English-language blogs
}

\author{
Shrouq Al Maghlouth \\ King Faisal University, Saudi Arabia, salmaghlouth@kfu.edu.sa
}

\begin{abstract}
This paper examines the discourse on social change in women-related posts on Saudi English-language blogs. These posts negotiate many reforming measures proposed by the Saudi government to facilitate more women's empowerment. An eclectic approach to intertextuality is adopted to explore the virtual community and the connections created on such platforms. The methodology adopted is based on Koller's (2012) work on analyzing collective identities and draws primarily on Reisigl \& Wodak's $(2009,90)$ view of Intertextuality. It also examines more direct and explicit instances of the recontextualization of other texts or discourses through hyperlinked clauses on such blogs. The findings of the analysis reveal that the community at hand is quite closed, exhibiting an example of what has been identified in psychology as confirmation bias (Nickerson 1998, 175), which jeopardizes the potential of blogging for promoting change. A supporter/opponent struggle is vigorously expressed in these posts, to the point that it overlooks the bigger picture, i.e. women's empowerment. Women who are expected to be at the centre of these topics are sidelined by such struggles.
\end{abstract}

KEYWORDS: blogging, critical discourse analysis, social change, women's empowerment

\section{Introduction}

This paper is based on a doctoral thesis examining the relationship between discourse and context in light of the socio-cognitive approach (Al Maghlouth 2017). It conducts a critical discourse analysis (henceforth CDA) study on how social change was called for between 2009-2012 in Saudi English-language blogs. While these blogs often discuss a wide range of topics related to social change in the Kingdom of Saudi Arabia (henceforth KSA), this paper in particular only examines those relevant to women's empowerment on the Saudi scene.

\section{Discourse, Critical Discourse Analysis and Social Change}

With this in mind, it is essential to define discourse and introduce briefly the socio-cognitive approach to CDA. Wodak \& Meyer $(2009,5)$, for instance, cite the following definition as a favourable one in CDA literature:

CDA sees discourse - language use in speech and writing - as a form of 'social practice'. Describing discourse as social practice implies a dialectical relationship between a particular discursive event and the situation(s), institution(s), and social structure(s), which frame it: The discursive event is shaped by them, but it also shapes them. That is, discourse is socially constitutive as well as socially conditioned - it constitutes situations, objects of knowledge, and the social identities of and relationships between people and groups of people. It is constitutive both in the sense that it helps to sustain and reproduce the social status quo, and in the sense that it contributes to transforming it. Since discourse is so socially consequential, it gives rise to important issues of power. Discursive practices may have major ideological effects - that is, they can help produce and reproduce unequal power relations between (for instance) social class, women and men, and ethnic/cultural majorities and minorities through the ways in which they represent things and position things. (Fairclough \& Wodak 1997, 258)

This excerpt highlights the socially constitutive and constituting nature of discourse, and in light of this, CDA emerges as an 'analytical practice' with 'an attitude' (van Dijk 2015, 466). Thus, for van Dijk, CDA examines social power distribution as manifested, maintained, reproduced, legitimated and challenged by discourse in order to rectify inequalities and abuse. From such a perspective, CDA can be presented as a 'social movement' with an activist essence. While CDA has a diversity of approaches, this paper approaches it from a socio-cognitive perspective (van Dijk 2009). Such an approach is based on the theory of social representation (Moscovici 2000) and the discourse-cognition-society triangle (van Dijk 2009, 
64). Of key significance within such approach is the notion of mental models, which are 'representations of the events and situations observed, participated in or referred to by discourse' (van Dijk 2009, 65). Hence, it is worth pointing out what mental models are being negotiated within the discourse in question and, more importantly, how they are distributed discursively. This is done while taking into consideration that mental representations cannot be identified explicitly and overtly within discourse but are rather inferred indirectly from diverse linguistic and non-linguistic pieces of evidence within the same context.

The original framework of analysis (Koller 2012) is threefold, it examines three layers of discourse, the textual, discursive and socio-cognitive levels, in order to identify these mental models and how they are manifested, distributed or challenged within discourse. However, this paper targets only the second level, examining the connections and communities created by and simultaneously creating discourse in light of the aforementioned notion of mental representations. This does not mean that such levels should be examined separately. On the contrary, the elements on each level have a reciprocal relationship with others across different levels, but for the sake of analysis it is presented as such.

Since this paper attempts to highlight the potential of the blogs under study in terms of promoting social change on the discursive level, it is essential to discuss some of the literature on the feasibility of discourse, and consequently CDA, in relation to social change. For example, Bracher $(1993,53)$ differentiates between four essential social effects resulting from discourses: '(1) educating / indoctrinating; (2) governing / commanding; (3) desiring / protesting; (4) analyzing / transforming / revolutionizing'. With such power assigned to discourse, it is possible to envisage how groups clashing within the same social context, for example dominating and dominated ones, might employ these diverse effects accordingly. In this regard, Fairclough $(1992,201)$ introduces the notions of the 'technologisation' and 'democratization' of discourse. The first refers to cases where there is an intervention within social or discursive contexts to allow a dominant group hegemony over a dominated one. This often gives rise to what van Dijk $(1998,138)$ refers to as the ideology of 'dominance'. On the other hand, Fairclough sees the democratization of discourse as the opposite case when the intervention targets the removal of power inequalities within the same discursive context, which in turn should give more agency to the dominated group or at least those supporting them in such removal. Again, this can be linked to van Dijk's $(1998,138)$ 'competing ideologies', but with reference to the ideology of 'resistance'.

Plenty of recent research on gender inequality in discourse falls under the second category, as it pursues the democratization of discourse and the removal of gender asymmetries (Al Maghlouth 2017). In fact, the blog posts under examination claim to target this goal too, as they continuously discuss any attempts to change the status quo to allow women more rights and sometimes they take action in support of that. Keeping in mind that they are also classified as online/digital discourses with open worldwide access, these platforms can be quite promising to promote change and negotiate mental representations in pursuit of more women's empowerment. This should, evidently, be considered in light of the time span under examination, 2009-2012, in which period a number of blogs flourished in Saudi Arabia. In the years that followed, however, blogging lost most of its popularity to alternative platforms for micro-blogging, such as Twitter and other social-media forums. This was inevitable with the surge in smartphone uptake, to the point that many wonder if blogging is actually dying - at least in Saudi Arabia.

\section{Intertextuality as an Inherent Feature of Online/Digital Discourses}

The above discussion has provided a brief review of discourse and CDA and how these are linked to social change. It has also established online/digital discourses as a promising area for promoting social change through virtual communities. A fundamental feature of online/digital discourses in general, and the blogging genre in particular, is the extensive use of hyperlinks within such posts (Myers 2010). Consequently, an examination of intertextuality is quite justified to understand exactly how discursive practices are used for the representation and distribution of mental models in support of change and competing ideologies within a given virtual community. In the next paragraphs, intertextuality is defined and explained along with the framework adopted in this paper. 
The origin of the definition presented here can be linked to Bakhtin's notion of heteroglossia (1981). In brief, within this notion, there are numerous voices and/or varieties which exist at the same time and in the same text, with varying degrees of power and existence. Hence, the task of the analyst becomes even more challenging when attempting to identify such voices and their links (Bolander \& Locher 2014). According to Reisigl and Wodak (2009, 90), intertextuality can be defined as the following:

\begin{abstract}
Intertextuality means that texts are linked to other texts, both in the past and in the present. Such connections are established in different ways: through explicit reference to a topic or main actor; through reference to the same events; by allusions or evocations; by the transfer of main arguments from one text to the next; and so on. The process of transferring given elements to new contexts is labelled recontextualization; if an element is taken out of a specific context, we observe the process of de-contextualisation; if the respective element is then inserted into a new context, we witness the process of recontextualization. The element (partly) acquires a new meaning, since meanings are formed in use.
\end{abstract}

This perception clearly identifies the relationship between intertextuality and discursive practices as the text producer intentionally decides to recontextualize a given text, event or reference to have a certain impact on his or her reader(s) (Al Maghlouth 2017). It is also quite relevant to include in this discussion further notions of Bakhtin's (1981), such as authoritative and persuasive discourses. The first one has a univocal, fixed and monologue-based nature, while the second reveals internal rhetorical features allowing for more dialogue (Wertsch 2001, 226-7). Along the same lines, Wetherell $(2001,19)$ proposes that when a multivoiced discourse is the case, text producers might assume any of the following roles: the author of what they say, the principal (the one the words are about) or the animator of someone else's words'. The next section highlights the methodology adopted in this paper as well as how the aforementioned notions are implemented to examine the discourse in question.

\title{
Methodology of Data Collection
}

Data were collected from posts on Saudi blogs exclusively in English. Four popular blogs during 20092012 were selected: saudiwoman, qusaytoday, saudijeans and riyadhbureau, all of which were posted on by Saudi bloggers. These were checked using the blogs' inbuilt search engines, as well as manual scanning through the archives. A total of 172 posts were found to be relevant to women's empowerment. A number of topics were discussed on these blogs, but five topics in particular appeared to be more prominent at that time, given the social and cognitive context when these were posted. The five topics are: women driving, women in sports, women in unconventional work environments, women in politics and gender segregation. A sample of 40 posts was randomly taken from the top five topics and the analysis included analyzing those posts after transcribing them into numbered clauses along with their comments. The clause-based transcription was based on systemic functional grammar (Halliday \& Mattiessen 2014), with the main verb as the centre of each clause.

Analysis on the discursive level consisted of two stages to ensure depth of examination. The first stage consisted exclusively of analyzing all the explicit hyperlinks embedded within the posts, whether these were embedded in the form of words or as explicit web addresses. The second stage involved going through instances of intertextuality which were not hyperlinked but still count as such. It also involved examining the multiplicity of voices as expressed in discourse, including those in the comments section, if any. Combining these two stages allowed the data to be analyzed both quantitatively and qualitatively.

\section{Analysis and Discussion}

Starting with the first stage, a total of 157 links were identified in the sample. Then, these were classified according to what they link to: same blogger's post (i.e. self), international webpages, local webpages and finally posts by other bloggers and supporters of similar causes. Table 1, below, shows the numbers and percentages of links to each category in all the sample and it is evident that these numbers are distributed at roughly similar percentages. However, a detailed examination of each topic separately reveals a 
different case. To illustrate, the nature of the topic itself dictated what kinds of hyperlinks were used. For example, in the topic on the inclusion of women in sports in particular, this topic at that time (2009-2012) was motivated by the International Olympic Committee pressuring the Saudi Olympic Committee to include women for the first time in its delegation. As a result to this, about $70 \%$ of links on that topic were to international pages. In contrast, on the topic of including women into politics as members of the Shoura (counselling) Council or as ministers, about $60 \%$ of the links were to other bloggers and supporters who were supporting this cause nationally.

Table 1. Distribution of hyperlinks in the whole sample (all five topics)

\begin{tabular}{|l|c|c|}
\hline Link to: & Number of links & Percentage \\
\hline Same blogger & 34 & $21.66 \%$ \\
\hline International webpages & 40 & $25.48 \%$ \\
\hline Local webpages & 48 & $30.57 \%$ \\
\hline Other bloggers/ supporters & 35 & $22.29 \%$ \\
\hline Total & 157 & $100 \%$ \\
\hline
\end{tabular}

What is evident, however, is the almost complete exclusion of those who oppose women's empowerment, despite the fact that they are clearly present in the non-hyperlinked stage. In other words, almost none of the identified links above actually link to any opponents; even when they are quoted and attacked, they are often not mentioned in any of the hyperlinks. But in non-hyperlinked cases, there are a number of recontextualization instances where opponents are allowed space linguistically but denied online access to such space. This should be understood in light of the struggle taking place between these bloggers and their supporters on the one hand and opponents on the other. This struggle is very severe, as manifested in the discourse, with bloggers repeatedly and continuously insisting on forming an extremely negative representation of their opponents while excluding them from having entry into their virtual world.

This is closely linked to the theme of US and THEM (van Dijk 1995), and theories of intergroup behaviour and conflict (cf. Fiske \& Taylor 2013 for further details). But briefly, the central premise underlying such a conception is the positive representation of the self, which is emphasized by the negative representation of others. Due to this, the recontextualization of racial references, such as the Apartheid in South Africa or the story of Rosa Parks, has been used consistently to cast the opponents as racists in the struggle towards more gender equality. While this might be reasonable and expected, considering the activist nature of this cause, the dilemma is that these bloggers have been too preoccupied with attacking their opponents at the expense of the cause per se. To illustrate, in many cases, the bloggers under study are the authors of their own posts and also animators of other's speech, including that of opponents. Nevertheless, women-whose rights are being defended hereare rarely given the same space to express their voices in the same defensive discourse. With very few exceptions, women are talked about in these posts far more than they do the talking.

Examining the comments section of all the posts also reveals a similar struggle and a similar exclusion of opponents. The vast majority are extremely supportive of the content of the posts promoting women's empowerment. Even in the very few cases where one or two opposing comments are found, they are immediately attacked, along with their posters, by other supportive commentators. This obviously signals the readership of such blogs, but it also signifies the presence of a closed virtual community between these bloggers and their supporters. In fact, the choice of writing in English - which is not the bloggers' first language and considered a foreign language in Saudi Arabia-signifies the exclusive nature of such a community. This community limits its negotiations exclusively to its members, which might be explained using a term borrowed from psychology, i.e. confirmation bias. Nickerson $(1998,175)$ suggests that confirmation bias, which is typically used in the psychological literature, connotes the seeking or interpreting of evidence in ways that are partial to existing beliefs, expectations or a hypothesis in hand'. Blogging often runs this risk as it allows participants to intentionally select who to subscribe to or follow and gives bloggers an extremely 
passionate and supportive audience. This is also consistent with another term borrowed from media studies, i.e. echo chambers, 'where only selected and supportive followers are encouraged to interact, in a way that affirms' the views of those they follow (Al Maghlouth 2017, 280).

\section{Conclusion}

The above discussion has highlighted the discursive practices surrounding the discourse supporting women's empowerment in Saudi English-language blogs. A brief examination of relevant literature on discourse and CDA has been offered, with a special focus on the relationship between discourse and social change. Then, the methodology for data collection and analysis was identified. The findings reveal that the discourse under study linguistically and discursively mirrors the socio-cognitive struggle taking place in the real world. But the results also show that they create a closely related virtual community with almost exclusive access to its supporters only. This, however, jeopardizes the potential of these blogs in terms of promoting change in the wider society, since it limits the negotiation of mental representations supporting women's empowerment to those who already support it. In sum, these blogs are unable to promote social change efficiently as they preach to the already converted.

\section{Acknowledgments}

The researcher would like to express her deep gratitude to the Saudi Ministry of Education and King Faisal University for generously funding this study.

\section{References}

Al Maghlouth, S. 2017. "Critical discourse analysis of social change in women-related posts on Saudi English-language blogs posted between 2009 and 2012". PhD diss., Lancaster University: UK.

Bakhtin, M. 1981. The dialogic imagination: four essays. M. Holquist (ed.), C. Emerson and M. Holquist (trans.). Austin: University of Texas Press.

Bolander, B., and M. Locher. 2014. "Doing sociolinguistic research on computer-mediated data: A review of four methodological issues." Discourse, Context \& Media, 3:14- 26.

Bracher, M. 1993. Lacan, discourse and social change: A psychoanalytic cultural criticism. London: Cornell University.

Fairclough, N. 1992. Discourse and social change. Cambridge: Polity.

Fairclough, N., and R. Wodak. 1997. "Critical discourse analysis." In Discourse as social interaction. Discourse studies: A multidisciplinary introduction, edited by T. van Dijk, 258-284. London: Sage.

Fiske, S., and S. Taylor. 2013. Social cognition: from brains to culture (2nd ed.). London: Sage.

Halliday, M., and C. Matthiessen. 2014. An introduction to functional grammar (4th ed.). London: Routledge.

Koller, V. 2012. "How to analyse collective identity in discourse-textual and contextual parameters." Critical Approaches to Discourse Analysis across Disciplines 5(2):19-38.

Moscovici, S. 2000. Social representations: explorations in social psychology. Oxford: Blackwell.

Myers, G. 2010. Discourse of blogs and wikis. London: Continuum.

Nickerson, R. 1998. "Confirmation bias: A ubiquitous phenomenon in many guises." Review of General Psychology 2(2): $175-220$.

Reisigl, M., and R. Wodak. 2009. "The discourse-historical approach (DHA)." In Methods of critical discourse analysis, edited by R. Wodak and M. Meyer, 87-122. London: Sage.

van Dijk, T. 1995. "Discourse analysis as ideology analysis." Language and Peace 10: 47-142.

van Dijk, T.1998. Ideology: A multidisciplinary approach. London: Sage.

van Dijk, T. 2009. "Critical discourse studies: A sociocognitive approach." In Methods of critical discourse analysis, edited by R. Wodak and M. Meyer, 62-86. London: Sage.

van Dijk, T. 2015. "Critical discourse analysis." In The handbook of critical discourse analysis, edited by D. Tannen, H. Hamilton, and D. Schiffrin. 466- 485. New Jersey: Wiley \& Sons.

Wertsch, J. 2001. "The multivoicedness of meaning." In Discourse theory and practice: A reader, edited by M. Wetherell, S. Taylor, and S. Yates, 222-235. London: Sage.

Wetherell, M. 2001. "Themes in discourse research: The case of Diana." In Discourse theory and practice: A reader, edited by M. Wetherell, S. Taylor, and S. Yates, 14-28. London: Sage.

Wodak, R., and M. Meyer. 2009. "Critical discourse analysis: History, agenda, theory, and methodology." In Methods of critical discourse analysis, edited by R. Wodak and M. Meyer, 1-33. London: Sage. 